\title{
Curing acceleration of cyanate ester resin by a phenolic compound having a tertiary
} amino group at the ortho-position

\author{
Keisuke IZU, Yuichiro TOKORO, Toshiyuki OYAMA* \\ Department of Chemistry and Life Science, Yokohama National University \\ 79-5 Tokiwadai, Hodogaya-ku, Yokohama 240-8501, Japan
}

*To whom correspondence should be addressed (Tel/Fax: +81-45-339-3961, E-mail:

oyama-toshiyuki-wz@ynu.ac.jp). 


\begin{abstract}
To develop a novel organic catalyst that can effectively cure cyanate ester resins, the effects of incorporating various phenolic compounds on the curing of bisphenol A dicyanate (BADCY) was investigated. Differential scanning calorimetry (DSC) and Fourier transform infrared (FT-IR) spectroscopy analyses revealed that o-(dimethylamino)methylphenol (o-DAMP) was a highly effective catalyst for accelerating the curing of BADCY, and the addition of $o$-DAMP reduced the final curing temperature of BADCY to $180{ }^{\circ} \mathrm{C}$. The promoting effect of $o$-DAMP was found to be due to the presence of an acidic phenolic $\mathrm{OH}$ group and a basic (dimethylamino)methyl group at the ortho-positions of the molecule. The addition of $o$-DAMP improved the modulus, strength and fracture toughness $\left(\mathrm{K}_{\mathrm{IC}}\right)$ of the cured BADCY resins. The mechanical and thermal properties of the cured resins could be adjusted by changing the amount of $o$-DAMP.
\end{abstract}

Keywords: curing acceleration / cyanate ester resin / $o$-(dimethylamino)methylphenol / thermosetting resin

Running head: Curing acceleration of cyanate resin by phenolic compounds 


\section{Introduction}

Cyanate ester resin is a high-performance thermosetting resin that forms a networked polymer by the cyclotrimerization reaction of cyanate ester groups to give a cured product with high heat resistance, low water absorption and high electrical insulation (Scheme 1). ${ }^{1-5}$ Based on these properties, cyanate ester resin is expected to be a promising candidate in many advanced applications, such as the high-performance encapsulating resin for electronic devices including $\mathrm{SiC}$ power semiconductor devices, high-temperature adhesives and structural materials for the aerospace industry. ${ }^{6-14}$

\section{(Scheme 1)}

However, cyanate ester resin has the disadvantage that the curing of the resin requires prolonged high temperatures $\left(250^{\circ} \mathrm{C}\right.$ or higher), and such curing can damage the product to which the resin is applied. To overcome this disadvantage, catalysts are usually added to the curing system to promote the polymerization of the resin. The most common catalysts are mixtures of carboxylates or chelate salts of transition metal ions $\left(\mathrm{Cu}^{2+}, \mathrm{Co}^{2+}, \mathrm{Zn}^{2+}\right.$, etc. $)$ and cocatalysts (such as $p$-nonylphenol), ${ }^{7}$ but curing at $230{ }^{\circ} \mathrm{C}$ or higher is usually required even in the presence of such catalysts. Furthermore, the metal ions in the catalyst remain in the cured resin, and these residual metal ions can adversely affect the properties of the cured resin. For these reasons, attempts have been made to promote the curing of cyanate ester resin by adding catalysts that do not contain metal ions. ${ }^{13-19}$ In particular, the addition of active hydrogen compounds containing alcoholic and phenolic $-\mathrm{OH}$ and $-\mathrm{NH}_{2}$ groups that can react with cyanate ester groups has been widely studied. ${ }^{13-16}$ For example, Ma et al reported that the addition of poly(ethylene glycol) promotes the polymerization of cyanate ester resins, ${ }^{15}$ and Lin et al cured cyanate ester resin at a final curing temperature of $200{ }^{\circ} \mathrm{C}$ by adding a 
polymeric microsphere with phenolic $-\mathrm{OH}$ or $-\mathrm{NH}_{2}$ groups. ${ }^{14}$ However, to our knowledge, few studies have successfully cured cyanate ester resin at a final curing temperature below $200{ }^{\circ} \mathrm{C}$ in the absence of metal ions.

Thus, we explored a novel nonmetallic catalyst that could cure a cyanate ester resin below $200{ }^{\circ} \mathrm{C}$ by using bisphenol A dicyanate (BADCY) as a typical cyanate ester resin. In this study, we focused on compounds having phenolic $\mathrm{OH}$ groups because they are readily available in various structures. To enhance the reactivity of the phenolic $\mathrm{OH}$ groups toward cyanate ester groups, we examined the addition of phenolic compounds having electron-donating groups and the activation of the phenolic $\mathrm{OH}$ groups by acid-base interactions. The resins were cured using the most effective catalyst in various amounts, and their thermal and mechanical properties were also investigated.

\section{Experimental}

\section{Materials}

The structures of the compounds used in this study are shown in Figure 1. BADCY was kindly donated by Mitsubishi Gas Chemical Company, Inc (Tokyo, Japan). $o$-(Dimethylamino)methylphenol (o-DAMP) (containing $22 \mathrm{~mol} \%$ phenol) and $p$-cresol were purchased from Tokyo Chemical Industry Co., Ltd (Tokyo, Japan). Phenol, o-cresol and p-methoxyphenol were purchased from FUJIFILM Wako Pure Chemical Corporation (Osaka, Japan). $p$-(Dimethylamino)methylphenol ( $p$-DAMP) was synthesized according to the literature. $^{20}$

\section{(Figure 1)}

\section{Preparation of the cured resins}


The preparation of the cured product of BADCY by using $o$-DAMP as the catalyst with a ratio between $\mathrm{OCN}$ in $\mathrm{BADCY}$ and $\mathrm{OH}$ in $o$-DAMP of $1.0: 0.05$ is described as a typical example. BADCY $(9.53 \mathrm{~g}, 68.4 \mathrm{mmol}$ of $\mathrm{OCN})$ was melted at $100{ }^{\circ} \mathrm{C}$ for $20 \mathrm{~min}$ and then naturally cooled to $90{ }^{\circ} \mathrm{C}$. $o$-DAMP $(0.465 \mathrm{~mL}, 3.42 \mathrm{mmol}$ of $\mathrm{OH})$ was added to the melted BADCY and mixed at $90{ }^{\circ} \mathrm{C}$ for $1 \mathrm{~min}$. The resulting mixture was molded to aluminum metal casting plates preheated at $90{ }^{\circ} \mathrm{C}$ and then degassed under reduced pressure for $20 \mathrm{~min}$ at this temperature. The molded and degassed mixture was heated at $120^{\circ} \mathrm{C} / 2 \mathrm{~h}+150{ }^{\circ} \mathrm{C} / 2 \mathrm{~h}$ $+180^{\circ} \mathrm{C} / 6 \mathrm{~h}$ to give a cured resin.

\section{Measurement}

Differential scanning calorimetry (DSC) analysis was performed on a DSC-60 (Shimadzu Corp. (Kyoto, Japan)) at a heating rate of $10{ }^{\circ} \mathrm{C} / \mathrm{min}$ under a nitrogen atmosphere to evaluate the effects of phenolic compounds on the curing of BADCY. The exothermic onset temperatures $\left(\mathrm{T}_{\text {onset }} \mathrm{S}\right)$ were determined from the intersections of the tangents of the DSC thermograms. Fourier transform infrared (FT-IR) spectra were acquired with a SPECTRUM ONE system (PerkinElmer Inc. (Waltham, MA, USA)) to examine the progress of the reaction in the actual curing process when preparing the cured products. Specimens for measuring the mechanical properties were prepared by cutting the obtained cured resins with a diamond saw and polishing the cut surface with sandpaper (P240, 800 and 800/2400). The flexural properties of the specimens were measured by a three-point bending test with an AG-X $10 \mathrm{kN}$ universal testing machine (Shimadzu Corp.) at a crosshead speed of $2 \mathrm{~mm} / \mathrm{min}$ according to JIS K7203. The critical stress intensity factor $\left(\mathrm{K}_{\mathrm{IC}}\right)$, as an index of fracture toughness, was measured with an AG-X $10 \mathrm{kN}$ universal testing machine (Shimadzu Corp.) at a crosshead speed of $10 \mathrm{~mm} / \mathrm{min}$ according to ASTM D5045. Dynamic mechanical analysis (DMA) was performed on a DMS6100 system (SII NanoTechnology Inc. (Tokyo, 
Japan)) at a heating rate of $5{ }^{\circ} \mathrm{C} / \mathrm{min}$ and a frequency of $1.0 \mathrm{~Hz}$ under an air atmosphere. Thermogravimetric analysis (TGA) was performed on a TGA-50 instrument (Shimadzu Corp.) at a heating rate of $10^{\circ} \mathrm{C} / \mathrm{min}$ under a nitrogen atmosphere.

\section{Results and Discussion}

\section{Effects of adding various phenolic compounds on the reaction behavior of BADCY}

DSC analyses of the mixtures between BADCY and various phenolic compounds were performed at a ratio of $\mathrm{OCN} / \mathrm{OH}=1.0 / 0.05$ to investigate the effects of the structures of the phenolic compounds on the reaction behavior. The results of the DSC analyses are shown in Figure 2, and their $\mathrm{T}_{\text {onset }} \mathrm{S}$ and peak temperatures $\left(\mathrm{T}_{\text {peak }} \mathrm{S}\right)$ are provided in Table 1. BADCY itself showed $\mathrm{T}_{\text {onset }}$ and $\mathrm{T}_{\text {peak }}$ at $271{ }^{\circ} \mathrm{C}$ and $311^{\circ} \mathrm{C}$, respectively, while $\mathrm{T}_{\text {onset }}$ and $\mathrm{T}_{\text {peak }}$ of BADCY/phenol were observed at $197^{\circ} \mathrm{C}$ and $272^{\circ} \mathrm{C}$. These results indicate that the addition of phenol promotes the curing of the cyanate ester resin, as reported in the previous literature. $^{13,16}$

\section{(Figure 2)}

\section{(Table 1)}

The addition of phenolic compounds with electron-donating groups, which are expected to increase the nucleophilicity of the phenolic $\mathrm{OH}$ groups, was then examined. The DSC analysis of the mixtures between BADCY and $o$-cresol, $p$-cresol or $p$-methoxyphenol caused

further decreases in $\mathrm{T}_{\text {onset }} \mathrm{S}$ (Figure 2 and Table 1). In particular, the $\mathrm{T}_{\text {onset }}$ of BADCY/p-methoxyphenol was at $173{ }^{\circ} \mathrm{C}$, which is $24^{\circ} \mathrm{C}$ lower than that of BADCY/phenol. 
On the other hand, it was found that their $\mathrm{T}_{\text {peak }}$ s hardly changed. These results suggest that the introduction of electron-donating groups into the phenol structure does not sufficiently promote the curing of cyanate ester resins.

Then, we investigated the use of acid-base interactions to enhance the reactivity of the phenolic $\mathrm{OH}$ groups. The effects of the addition of $o$-DAMP, which possesses both phenolic $\mathrm{OH}$ and tertiary amino groups, on the exothermic behavior of BADCY were examined. The acid-base interactions between the phenolic $\mathrm{OH}$ and (dimethylamino)methyl groups are expected to enhance the nucleophilicity of the hydroxyl group by attracting the proton of the $\mathrm{OH}$ to the amino group, thereby promoting the reaction between the phenolic $\mathrm{OH}$ and the cyanate ester groups. The results of the DSC analyses with and without $o$-DAMP are shown in Figure 3 and Table 1. The $\mathrm{T}_{\text {onset }}$ and the main $\mathrm{T}_{\text {peak }}$ of BADCY/o-DAMP were at $108{ }^{\circ} \mathrm{C}$ and $194{ }^{\circ} \mathrm{C}$, and these temperatures were found to be $89{ }^{\circ} \mathrm{C}$ and $78{ }^{\circ} \mathrm{C}$ lower than those of BADCY/phenol, respectively. This result indicates that the activation of the phenolic $\mathrm{OH}$ groups by acid-base interactions is effective for promoting the curing of cyanate ester resins.

\section{(Figure 3)}

To further investigate the effects of introducing a (dimethylamino)methyl group on phenolic compounds, BADCY/p-DAMP was analyzed by DSC (Figure 3, Table 1). The exothermic behavior of BADCY/p-DAMP was found to be different from that of BADCY/o-DAMP, with the $\mathrm{T}_{\text {onset }}$ and $\mathrm{T}_{\text {peak }}$ of the former being $34{ }^{\circ} \mathrm{C}$ and $14{ }^{\circ} \mathrm{C}$ higher than those of the latter, respectively. This result demonstrates that introducing a tertiary amino group at the ortho-position of the phenolic $\mathrm{OH}$ group is more effective for curing than introducing the same group at the para-position. We also measured FT-IR spectra of the mixtures of BADCY with $o$-DAMP, $p$-DAMP and phenol before the DSC measurements to 
elucidate the mechanism of the reaction promotion. The results are shown in Figure 4, and the absorption of iminocarbonate $(-\mathrm{O}-\mathrm{C}(=\mathrm{NH})-\mathrm{O}-)^{11,15,21,22}$ at $1680 \mathrm{~cm}^{-1}$ appeared in the spectra of BADCY/o-DAMP and BADCY/p-DAMP, while no such absorption was observed in the spectrum of BADCY/phenol. This indicates that both the intramolecular acid-base interaction of $o$-DAMP and the intermolecular acid-base interaction of $p$-DAMP can effectively promote the reaction between the phenolic $\mathrm{OH}$ and cyanate ester to form an iminocarbonate group.

\section{(Figure 4)}

These results suggest that the acid-base interactions caused by the introduction of a tertiary amino group may promote the reaction between $\mathrm{OCN}$ and phenolic $\mathrm{OH}$ groups to form an iminocarbonate that can be cyclotrimerized with another two monomers (Scheme 2a). In addition, when the tertiary amino group is located ortho to the $\mathrm{OH}$ group, intramolecular cyclization between the iminocarbonate and the tertiary amino group would further form an intermediate with a six-membered ring structure (Scheme $2 b$ ), and this reactive intermediate would readily react with two more $\mathrm{OCN}$ groups to give a triazine ring with an $o$-DAMP

moiety (Scheme 2c). The resulting product has two basic groups (the triazine ring ${ }^{23}$ and the (dimethylamino)methyl group), and these are expected to promote the reaction between the cyanate ester and the Ar-OH released during the reaction in Scheme 2 by intermolecular acid-base interactions, which accelerates the overall curing reaction of this system. ${ }^{24,25}$ Although direct spectral evidence of the incorporation of $o$-DAMP into the network of BADCY has not been obtained, the crosslink density of the cured resin decreased as the amount of $o$-DAMP was increased, which suggests the incorporation of $o$-DAMP into the polymer network (see the section "Properties of the BADCYs cured in the presence of 
o-DAMP as a catalyst").

\section{(Scheme 2)}

The effects of the amount of $o$-DAMP on the reaction behavior were also investigated by using DSC analysis. The results are shown in Figure S1 and Table 1, and it was confirmed that the $\mathrm{T}_{\text {peak }}$ of BADCY/o-DAMP decreased as the amount of $o$-DAMP increased.

\section{Curing behavior of the BADCY/o-DAMP system}

We then examined the curing behavior of BADCY/o-DAMP under stepwise heating, which is commonly used in the actual preparation of cured cyanate ester resin products. The cured resins were prepared under stepwise heating conditions with final curing temperatures of 170 and $180^{\circ} \mathrm{C}$, and the progress of the curing was monitored based on the decrease in the absorption of the OCN group at $2235 \mathrm{~cm}^{-1}$ relative to the absorption of the phenyl group at $1503 \mathrm{~cm}^{-1}$ in the FT-IR spectra (Figure 5). The ratio between the absorptions of the OCN and phenyl groups (A-ocN/A-phenyl) in the cured resin prepared at a final curing temperature of $180{ }^{\circ} \mathrm{C}$ was 0.027 , while the A-ocN/A-phenyl of the cured resin prepared at a final curing temperature of $170{ }^{\circ} \mathrm{C}$ was 0.046 . These results suggest that the progress of the curing is better when the final curing temperature is $180^{\circ} \mathrm{C}$. We also conducted DMA of the cured resins to evaluate the effect of the final curing temperatures on the properties of the cured resins (Figure 6). In the tan $\delta$ plot of the resin cured at a final curing temperature of $180{ }^{\circ} \mathrm{C}$, a single peak was observed at $241{ }^{\circ} \mathrm{C}$, which suggests sufficient curing of the resin. However, a shoulder peak was observed at $220^{\circ} \mathrm{C}$ along with the main peak at $250{ }^{\circ} \mathrm{C}$ in the $\tan \delta$ plot of the resin cured at a final temperature of $170{ }^{\circ} \mathrm{C}$. The appearance of the two peaks indicates 
insufficient curing under these conditions; that is, the original $\mathrm{T}_{\mathrm{g}}$ of the cured resin would be $220^{\circ} \mathrm{C}$, and when the measuring temperature of the DMA exceeds this temperature, the remaining OCN groups would react again to raise the $T_{g}$. The results of the FT-IR and DMA measurements show that the utilization of $o$-DAMP as a catalyst enables the production of a sufficiently cured BADCY at a final curing temperature of $180^{\circ} \mathrm{C}$, which is lower than the curing temperatures required with existing catalysts.

(Figure 5)

\section{(Figure 6)}

The FT-IR spectra of the BADCY/o-DAMP system were then acquired at each curing step to examine the curing behavior in detail (Figure 7). The intensities of the absorptions of OCN at $2235 \mathrm{~cm}^{-1}$ and iminocarbonate group at $1680 \mathrm{~cm}^{-1}$ decreased, and the absorptions assignable to triazine ring at 1565 and $1367 \mathrm{~cm}^{-1}$ increased in intensity as the curing proceeded. The FT-IR spectra of BADCY without a catalyst were also measured at each curing step (Figure S2), and the change in A-ocN/A-phenyl for each curing step in BADCY/o-DAMP was compared to the changes in BADCY without a catalyst (Figure 8). The A-ocN $/ \mathrm{A}_{\text {-phenyl }}$ of BADCY/o-DAMP was found to be much smaller than that of BADCY without a catalyst from the early stages of curing. In addition, the increase in the absorptions of the triazine ring in BADCY/o-DAMP was larger than that in BADCY without a catalyst from the early stages of curing, especially at $120{ }^{\circ} \mathrm{C} / 2 \mathrm{~h}$ and $120{ }^{\circ} \mathrm{C} / 2 \mathrm{~h}+150{ }^{\circ} \mathrm{C} / 2 \mathrm{~h}$ (see Figures 7 and S2). These results suggest that the addition of $o$-DAMP is a very effective strategy for promoting the curing of cyanate ester resins. 


\section{(Figure 7)}

\section{(Figure 8)}

Furthermore, the effect of the amount of $o$-DAMP on the curing of BADCY was investigated. The FT-IR spectra of the BADCYs cured up to a final curing temperature of $180{ }^{\circ} \mathrm{C}$ with different amounts of $o$-DAMP were measured, and the results are shown in Figure S3. In all the spectra, large absorptions for the triazine ring were observed at 1565 and $1367 \mathrm{~cm}^{-1}$. On the other hand, the absorption of OCN at $2235 \mathrm{~cm}^{-1}$ decreased with increasing amount of $o$-DAMP, and it almost completely disappeared when the ratio of $\mathrm{OH}$ in $o$-DAMP to $\mathrm{OCN}$ in BADCY was 0.05 or more. We also conducted DMA of the BADCYs cured up to a final curing temperature of $180{ }^{\circ} \mathrm{C}$ with different amounts of $o$-DAMP (Figure 9). The numbers at the right of the sample names indicate the ratio of $\mathrm{OH}$ in $o$-DAMP to OCN in BADCY. The results of BADCY cured without any catalyst clearly indicated that the resin was not sufficiently cured. The tan $\delta$ plot of BADCY/o-DAMP0.03 showed a peak at $258^{\circ} \mathrm{C}$ with shoulder peaks at lower temperatures. The presence of such peaks suggests insufficient curing of the resin. In other words, the unreacted OCN groups would react at temperatures higher than the shoulder peak temperatures, thereby increasing the $T_{g}$ of the resin. On the other hand, such behavior was not observed in the tan $\delta$ plots for the cured resins with a ratio of $\mathrm{OH}$ in $o$-DAMP to $\mathrm{OCN}$ in BADCY was 0.05 or more, and these results were in agreement with those of the FT-IR spectra (Figure S3). The results of the FT-IR and DMA measurements shown above revealed that BADCY can be sufficiently cured at a final curing temperature of $180{ }^{\circ} \mathrm{C}$ by adding $o$-DAMP with a ratio of $\mathrm{OH}$ in $o$-DAMP to OCN in 
BADCY was 0.05 or more.

\section{(Figure 9)}

\section{Properties of the BADCYs cured in the presence of $o$-DAMP as a catalyst}

The mechanical and thermal properties of the BADCYs cured up to a final curing temperature of $180{ }^{\circ} \mathrm{C}$ with varying amounts of $o$-DAMP are shown in Table 2. For comparison, the mechanical properties, crosslink density and $\mathrm{T}_{\mathrm{g}}$ of the BADCY cured in the absence of a catalyst by heating to a final curing temperature of $250{ }^{\circ} \mathrm{C}$ are also shown in the table. The flexural modulus and the strength of the cured resins were found to be increased by the addition of $o$-DAMP. The fracture toughness $\left(\mathrm{K}_{\mathrm{IC}}\right)$ of BADCY/o-DAMP also increased with increasing amounts of $o$-DAMP. On the other hand, the $\mathrm{T}_{\mathrm{gs}}$ determined from the $\tan \delta$ peaks of the DMA charts (Figure 9) and $\mathrm{T}_{\mathrm{d} 5 \mathrm{~S}}$ and char yields obtained from TGA charts (Figure S4) decreased as the amount of $o$-DAMP increased. These results indicate that the thermal and mechanical properties of the cured resins can be tuned by changing the amount of $o$-DAMP, and the most balanced properties were obtained with BADCY/o-DAMP0.05.

\section{(Table 2)}

The changes in the thermal and mechanical properties shown above can be explained by the decrease in the degree of crosslinking with increasing amounts of $o$-DAMP. The crosslink density calculated by $E^{\prime} / \mathrm{RT}$, where $\mathrm{E}^{\prime}$ is the smallest value of the storage modulus in the rubbery plateau, $\mathrm{R}$ is the gas constant and $\mathrm{T}$ is the absolute temperature, ${ }^{26-28}$ actually decreased with increasing amounts of $o$-DAMP (Table 2). As shown in Scheme 2, $o$-DAMP 
is considered to be incorporated into the network structure, and this incorporation reduces the degree of crosslinking, decreasing the thermal properties. On the other hand, the decrease in the degree of crosslinking increases the motion of the chains between the crosslinking points and would allow effective packing of the chains during cooling after curing. As a result, the interactions between the chains in the cured resins would be increased, improving their mechanical properties. A similar relationship between the degree of crosslinking and the packing of the chains has also been reported for epoxy resins. ${ }^{29}$

\section{Conclusion}

The effect of adding various phenolic compounds on the curing of BADCY was examined, and the introduction of a (dimethylamino)methyl group into the phenolic structure was found to be effective for curing acceleration. The use of $o$-DAMP with a (dimethylamino)methyl group ortho to the phenolic $\mathrm{OH}$ group was particularly effective, and sufficient curing of BADCY at the final curing temperature of $180^{\circ} \mathrm{C}$ was achieved by adding $o$-DAMP at a ratio of $\mathrm{OH}$ in $o$-DAMP to $\mathrm{OCN}$ in BADCY was 0.05 or more. The resulting cured products had better mechanical properties, including modulus, strength and fracture toughness than the fully cured BADCY without any catalyst. In addition, the mechanical and thermal properties of the cured BADCY could be adjusted by changing the amount of $o$-DAMP, which is expected to be suitable for industrial applications. The curing mechanisms and curing kinetics of BADCY in the presence of $o$-DAMP are currently being investigated in more detail, and the results will be reported elsewhere.

\section{References}

1) H. Sato, Y. Nabae, T. Hayakawa, M. Kakimoto, J. Photopolym. Sci. Technol., 26, 373376 (2013). 
2) X. Zhang, F. Wang, Y. Zhu and H. Qi, RSC Adv., 9, 36424-36433 (2019).

3) Y. Lin, M. Song, React. Funct. Polym., 129, 58-63 (2018).

4) P. Ma, C. Dai, S. Jiang, Polymers, 11, 1458 (2019).

5) Z. Zhang, W. Xu, L. Yuan, Q. Guan, G. Liang, A. Gu, J. Appl. Polym. Sci., 135, 46587 (2018).

6) A. Matallana, E. Ibarra, I. Lopez, J. Andreu, J. I. Gerate, X. Jorda, J. Rebollo, Renewable and Sustainable Energy Reviews, 113, 109264 (2019).

7) T. Fang, D. A. Prog. Polym. Sci., 20, 61-118 (1995).

8) Z. Fang, J. Wang, A. Gu, Polym. Eng. Sci., 46, 670-679 (2006).

9) J. Wang, G. Liang, W. Zhao, S. Lü, H. Yan, Polym. Eng. Sci., 46, 581-587 (2006).

10) A. Gu, Comp. Sci. Technol., 66, 1749-1755 (2006).

11) K. Liang, G. Li, H. Toghiani, J. H. Koo, C. U. Pittman, Chem. Mater., 18, 301-312 (2006).

12) A. Ganesan, S. Muthusamy, J. Polym. Res., 15, 507-514 (2008).

13) P. Huang, A. Gu, G. Liang, L. Yuan, J. Appl. Polym. Sci., 121, 2113-2122 (2011).

14) C. Lin, L. Yuan, A. Gu, F. Chen, G. Liang, Compos. Sci. Technol., 85, 148-155 (2013).

15) J. Ma, X. Lei, D. Tian, L. Yuan, C. Liao, J. Appl. Polym. Sci., 132, 41841 (2015).

16) X. Chen, G. Liang, A. Gu, Li. Yuan, Ind. Eng. Chem. Res., 54, 1806-1815 (2015).

17) T. Kobayashi, M. Isono, T. Oyama, A. Takahashi, J. Network Polym., Jpn., 33, 130-139 (2012).

18) G. Liang, P. Ren, Z. Zhang, T. Lu, J. Appl. Polym. Sci., 101, 1744-1750 (2006).

19) M. W. Weng, R. J. Jeng, C. H. Lin, Macromolecules, 48, 2417-2421 (2015).

20) A. Johansson, C. Löfberg, M. Antonsson, S. von Unge, M. A. Hayes, R. Judkins, K. Ploj, L. Benthem, D. Lindén, P. Brodin, M. Wennerberg, M. Fredenwall, L. Li, J. Persson, R. 
Bergman, A. Pettersen, P. Gennemark, A. Hogner, J. Med. Chem., 59, 2497-2511 (2016).

21) M. Bauer, J. Bauer, G. Kühn, Acta Polym., 37, 715-719 (1986).

22) T. Iijima, S. Katsurayama, W. Fukuda, M. Tomoi, J. Appl. Polym. Sci., 76, 208-219 (2000).

23) H. Fujita, N. Hayakawa, M. Kunishima, J. Org. Chem., 80, 11200-11205 (2015).

24) K.-F. Lin, J.-Y. Shyu, J. Polym. Sci.: Part A: Polym. Chem., 39, 3085-3092 (2001).

25) J.-Y. Chang, J.-L. Hong, Polymer, 42, 1525-1532 (2001).

26) M. Kim, H. Ko, S.-M. Park, Compos. B: Eng., 170, 19-30 (2019).

27) J. Zhang, S. Xu, Mater. Express, 9, 337-343 (2019).

28) S. Khorshidi, A. Karkhaneh, S. Bonakdar, M. Omidian, J. Appl. Polym. Sci., 137, 48859 (2020).

29) M. Ochi, K. Yamashita, M. Yoshizumi, J. Appl. Polym Sci., 38, 789-799 (1989). 
Figure legends

Scheme 1 Cyclotrimerization of cyanate ester resin

Scheme 2 Presumed curing mechanism of cyanate ester resin in the presence of $o$-DAMP

Figure 1 Chemical structures of the compounds used in this study

Figure 2 DSC thermograms of BADCYs in the absence and presence of phenolic compounds $(\mathrm{OCN} / \mathrm{OH}=1.0 / 0.05)$.

Figure 3 DSC thermograms of BADCYs in the absence and presence of phenol, $o$-DAMP and $p$-DAMP $(\mathrm{OCN} / \mathrm{OH}=1.0 / 0.05)$.

Figure 4 FT-IR spectra of (a) BADCY/o-DAMP, (b) BADCY/p-DAMP and (c) $\mathrm{BADCY} /$ phenol before the DSC measurements $(\mathrm{OCN} / \mathrm{OH}=1.0 / 0.05)$.

Figure 5 FT-IR spectra of BADCY/o-DAMPs cured at (a) $120{ }^{\circ} \mathrm{C} / 2 \mathrm{~h}+150{ }^{\circ} \mathrm{C} / 2 \mathrm{~h}+$ $170{ }^{\circ} \mathrm{C} / 6 \mathrm{~h}$ and (b) $120^{\circ} \mathrm{C} / 2 \mathrm{~h}+150{ }^{\circ} \mathrm{C} / 2 \mathrm{~h}+180^{\circ} \mathrm{C} / 6 \mathrm{~h}(\mathrm{OCN} / \mathrm{OH}=1.0 / 0.05)$.

Figure 6 DMA results of BADCY/o-DAMPs cured under different conditions $(\mathrm{OCN} / \mathrm{OH}=$ $1.0 / 0.05)$.

Figure 7 FT-IR spectra of BADCY/o-DAMP at each curing step $(\mathrm{OCN} / \mathrm{OH}=1.0 / 0.05)$; (i) before curing, (ii) after $120^{\circ} \mathrm{C} / 2 \mathrm{~h}$, (iii) after $120^{\circ} \mathrm{C} / 2 \mathrm{~h}+150{ }^{\circ} \mathrm{C} / 2 \mathrm{~h}$, (iv) after $120^{\circ} \mathrm{C} / 2 \mathrm{~h}+$ $150{ }^{\circ} \mathrm{C} / 2 \mathrm{~h}+180^{\circ} \mathrm{C} / 2 \mathrm{~h}$, and (v) after $120^{\circ} \mathrm{C} / 2 \mathrm{~h}+150^{\circ} \mathrm{C} / 2 \mathrm{~h}+180^{\circ} \mathrm{C} / 6 \mathrm{~h}$.

Figure 8 Changes in A-ocN/A-phenyl for each curing step in BADCY/o-DAMP (OCN/OH = 1.0/0.05) and BADCY without a catalyst; (i) before curing, (ii) after $120^{\circ} \mathrm{C} / 2 \mathrm{~h}$, (iii) after $120{ }^{\circ} \mathrm{C} / 2 \mathrm{~h}+150{ }^{\circ} \mathrm{C} / 2 \mathrm{~h}$, (iv) after $120{ }^{\circ} \mathrm{C} / 2 \mathrm{~h}+150{ }^{\circ} \mathrm{C} / 2 \mathrm{~h}+180{ }^{\circ} \mathrm{C} / 2 \mathrm{~h}$, and (v) after $120^{\circ} \mathrm{C} / 2 \mathrm{~h}+150{ }^{\circ} \mathrm{C} / 2 \mathrm{~h}+180^{\circ} \mathrm{C} / 6 \mathrm{~h}$. 
Figure 9 DMA results of BADCY/o-DAMPs with different ratios between OCN in BADCY and $\mathrm{OH}$ in $o$-DAMP.

Table 1 The results of the DSC analysis of the mixtures between BADCY and phenolic compounds ${ }^{1)}$

\begin{tabular}{cccc}
\hline Phenolic compound & OH/OCN & $\begin{array}{c}\mathrm{T}_{\text {onset }} \\
{\left[{ }^{\circ} \mathrm{C}\right]}\end{array}$ & $\begin{array}{c}\mathrm{T}_{\text {peak }} \\
{\left[{ }^{\circ} \mathrm{C}\right]}\end{array}$ \\
\hline none & - & 271 & 311 \\
phenol & 0.05 & 197 & 272 \\
$o$-cresol & 0.05 & 187 & 267 \\
$p$-cresol & 0.05 & 189 & 265 \\
$p$ - methoxyphenol $^{2)}$ & 0.05 & 173 & 266 \\
$o$-DAMP & 0.05 & 108 & 141,194 \\
$p$-DAMP & 0.05 & 142 & 208 \\
\hline$o$-DAMP & 0.03 & 110 & 144,242 \\
$o-$ DAMP $^{2)}$ & 0.07 & 103 & 136,183 \\
$o$-DAMP & & 108 & 136,186 \\
\hline-
\end{tabular}

1) Heating rate: $10{ }^{\circ} \mathrm{C} / \mathrm{min}$, under $\mathrm{N}_{2}(50 \mathrm{~mL} / \mathrm{min})$

2) containing $22 \mathrm{~mol} \%$ phenol

Table 2 Mechanical and thermal properties of BADCY/o-DAMPs with different ratios between OCN in BADCY and $\mathrm{OH}$ in $o-\mathrm{DAMP}^{1)}$ 


\begin{tabular}{|c|c|c|c|c|c|c|c|}
\hline \multirow[b]{2}{*}{ Sample } & \multicolumn{2}{|c|}{ Flexural properties } & \multirow[b]{2}{*}{$\begin{array}{c}\mathrm{K}_{\mathrm{IC}} \\
{\left[\mathrm{MN} / \mathrm{m}^{3 / 2}\right]}\end{array}$} & \multirow{2}{*}{$\begin{array}{l}\text { Crosslink } \\
\text { density }^{2,3)} \\
{\left[\mathrm{kmol} / \mathrm{m}^{3}\right]}\end{array}$} & \multirow[b]{2}{*}{$\begin{array}{l}\mathrm{T}_{\mathrm{g}}^{2)} \\
{\left[{ }^{\circ} \mathrm{C}\right]}\end{array}$} & \multirow[b]{2}{*}{$\begin{array}{l}\mathrm{T}_{\mathrm{d} 5}{ }^{4)} \\
{\left[{ }^{\circ} \mathrm{C}\right]}\end{array}$} & \multirow[b]{2}{*}{$\begin{array}{c}\text { Char yield }^{4,5} \\
{[\%]}\end{array}$} \\
\hline & $\begin{array}{c}\text { Modulus } \\
{[\mathrm{GPa}]}\end{array}$ & $\begin{array}{c}\text { Strength } \\
{[\mathrm{MPa}]}\end{array}$ & & & & & \\
\hline BADCY & $3.04 \pm 0.04^{6)}$ & $191 \pm 4^{6)}$ & $0.52 \pm 0.02^{6)}$ & $-^{7)},(1.86)^{6)}$ & $-{ }^{7)},(297)^{6)}$ & 389 & 35.1 \\
\hline BADCY/o-DAMP0.03 & $3.61 \pm 0.05$ & $204 \pm 13$ & $0.65 \pm 0.03$ & $(1.96)^{7)}$ & $(258)^{7)}$ & 342 & 30.9 \\
\hline BADCY/o-DAMP0.05 & $3.70 \pm 0.05$ & $199 \pm 15$ & $0.66 \pm 0.02$ & 1.41 & 241 & 310 & 25.9 \\
\hline BADCY/o -DAMP0.07 & $3.42 \pm 0.13$ & $207 \pm 13$ & $0.75 \pm 0.05$ & 1.21 & 224 & 293 & 27.9 \\
\hline BADCY/o-DAMP0.09 & $3.83 \pm 0.04$ & $188 \pm 13$ & $0.87 \pm 0.07$ & 0.75 & 210 & 282 & 25.1 \\
\hline
\end{tabular}

1) Curing condition: $120{ }^{\circ} \mathrm{C} / 2 \mathrm{~h}+150{ }^{\circ} \mathrm{C} / 2 \mathrm{~h}+180{ }^{\circ} \mathrm{C} / 6 \mathrm{~h}$

2) By DMA (heating rate: $5^{\circ} \mathrm{C} / \mathrm{min}$, frequency: $1.0 \mathrm{~Hz}$ )

3) Calculated by $E^{\prime} / \mathrm{RT}$ ( $\mathrm{E}^{\prime}$ : the smallest value of the storage modulus at the rubbery plateau in DMA)

4) By TGA (heating rate: $5^{\circ} \mathrm{C} / \mathrm{min}$, under $\mathrm{N}_{2}, 50 \mathrm{~mL} / \mathrm{min}$ )

5) At $800{ }^{\circ} \mathrm{C}$

6) Value of the sample cured at $120^{\circ} \mathrm{C} / 2 \mathrm{~h}+150^{\circ} \mathrm{C} / 2 \mathrm{~h}+180^{\circ} \mathrm{C} / 2 \mathrm{~h}+200{ }^{\circ} \mathrm{C} / 4 \mathrm{~h}+250{ }^{\circ} \mathrm{C} / 2 \mathrm{~h}$

7) Insufficient curing was suggested in the DMA chart. 